\title{
Penerapan model cooperative learning tehnik example non example dalam meningkatan hasil belajar PAI kelas 4 di SDN 002 Balikpapan Timur
}

\author{
Imro Atus Sholikhah \\ SDN 008 Balikpapan Timur, Balikpapan, Indonesia \\ Email: alikadavi09@gmail.com
}

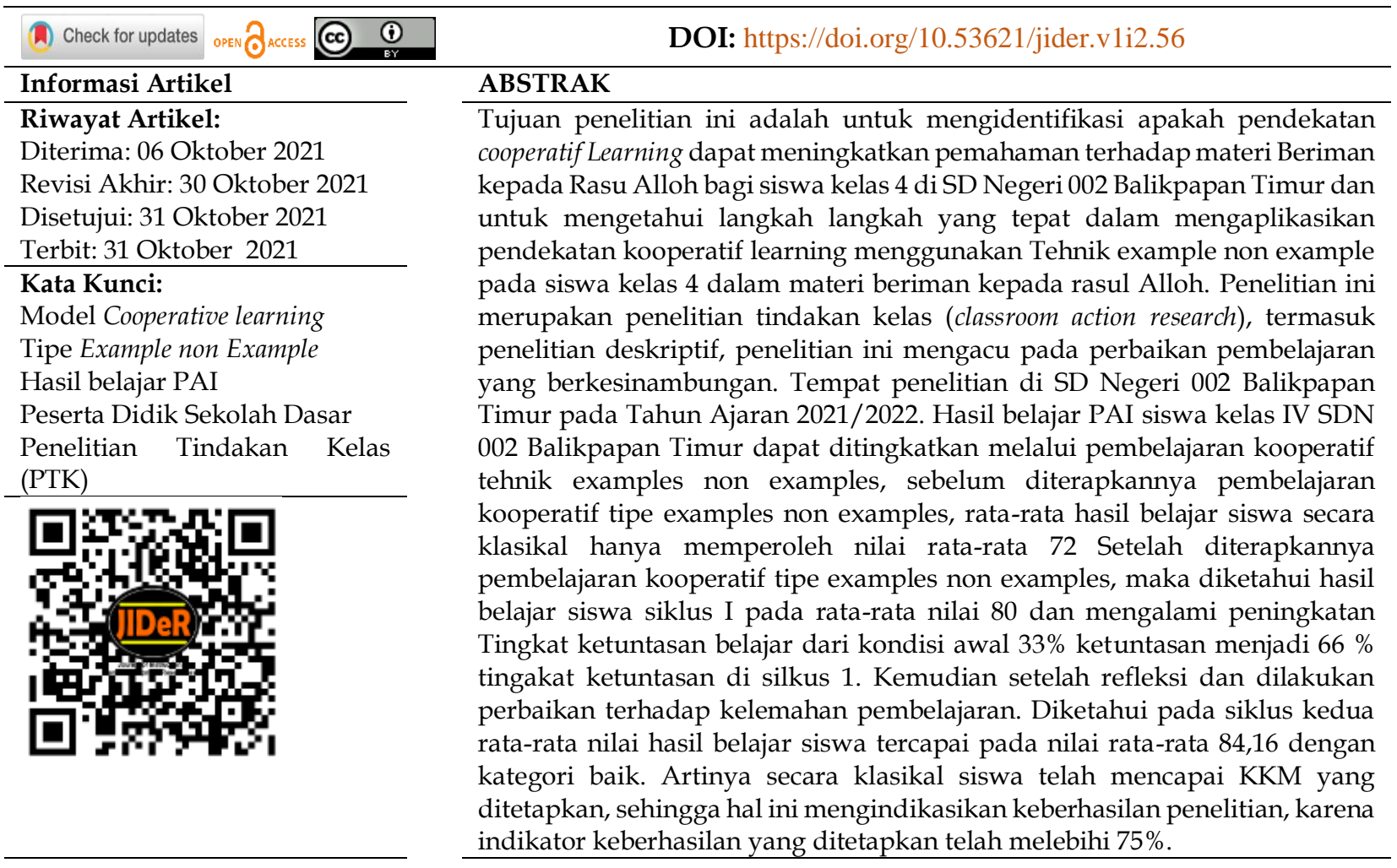

\section{PENDAHULUAN}

Karakteristik peserta didik menjadi bagian penting dalam pembelajaran termasuk dalam pendidikan Agama (Ainiyah, 2013; Wati, 2017), ada beberapa yang hal yang dapat memberikan pengaruh terahdap pendidikan dan karakter mulia siswa (Ariningsih \& Amalia, 2020), pengaruh bisa datang dari basic keluarganya yang mayoritas bekerja sebagai buruh tani dan pedagang kecil. Sehingga perhatian orang tua terhadap pendidikan anknya terbagi dan kurang optimal. Serta masalah lainnya adalah hampir $90 \%$ masalah kemampuan belajar anak diserahkan kepada pihak sekolah (Retnaningsih \& Afifah, 2019). Begitupun juga masalah Pendidikan Agama Islam terfokus hanya pada pembelajaran yang di dapat dari sekolah.

Faktor pendukung dapat memberikan wadah pendidikan pada peserta didik (Islamiah et al., 2019; Maryatun, 2016), dimana seperti TPA baru ada sekitar 2 tahun terakhir, sehingga anak anak sedikit mengalami kesusahan dalam pelajaran agama yang mulai dari kelas satu sudah harus dikenalkan dengan bacaan dan tulisan arap bersambung, Apalagi di kelas 4 yang mengharuskan anak minimal lancar membaca dan memahami teks, hal ini berkorelasi dengan materi tentang Beriman kpada Rasul Alloh yang didalamnya terdapat banyak kisah-kisah teladan dari berbagai sumber bacaan tentang kisah para nabi dan rasul (Ainiyah, 2013).

Materi tentang kisah beriman kepada rasul merupakan materi yang sangat penting karena didalamnya berisi kompetensi dasar yang harus dipahami dan diteladani oleh peserta didik. 
Penerapan model cooperative learning tehnik example non example dalam meningkatan hasil belajar PAI kelas 4 di SDN 002 Balikpapan Timur

Dalam materi ini peserta didik dituntut untuk memahami makna beriman kepada Rasul, bagaimana cara mengimaninya, apa saja sifat yang melekat sifat sifat yang ada pada nabi dan Rasul serta dapat memberikan contoh dalam kehidupan sehari-hari mereka, pengembangan bahan ajar perlu disesuaikan dengan model pembelajaran seperti Problem Based Learning dalam pembelajaran agama Islam (Syafei, 2019). Namun, sebagaimana pengalaman selama bertugas di sini, dalam ketrampilan membaca teks latin dan memahami banyak dari anak kelas 4 yang belum terlalu lancar membaca apalagi memahami teks bacaanya. Terkadang ketika guru mengajak anak untuk membaca di awal pembelajaran kemudian guru bertanya apa maksud dari bacaan tersebut anak ternyata tidak memahami isinya. Dan banyak juga dari siswa ketika diajak untuk mencari contoh perilaku yang menggambarkan keteladanan Nabi dan Rasul mereka belum bisa mengungkapkanya. Serta antusias semangat belajar terlihat sangat lemah terlihat dari kurang fokusnya mereka dengan pelajaran ketika KBM sedang berlangsung. Pembelajaran Pendidikan Agama Islam dan Budi Pekerti di sekolah yang menjadi tempat PPL kami yakni SD Negeri 002 Balikpapan Timur memiliki tantangan tersendiri.

Karena peneliti harus mencari data tentang subject yang akan kami teliti untuk memahami karakteristik peserta didik yang akan berhubungan dengan model pembelajaran yang akan kami gunakan. Beberapa model pembelajaran dapat dilaksanakan seperti model pembelajaran saat Covid-19 (Hairiah, 2021), model PjBL (Salehudin, 2020; Safaruddin, Degeng, et al., 2020; Safaruddin, Ibrahim, et al., 2020), PBL (Fitriani et al., 2020; Fuadi \& Muchson, 2020) dan sebagainya.

Padahal dalam kurikulum sekolah (Muhtar, 2014; Muslimin, 2016) menetapkan bahwa KKM sekolah untuk mata pelajaran Agama Islam pada kelas 4,5, dan 6 adalah 78. Pada kenyataanya ketika ulangan harian dari 12 siswa hampir $60 \%$ siswa dalam materi iman kepada rasul yang mendapatkan nilai dibawah KKM. Jadi lebih dari separuh siswa yang tidak tuntas dalam pembelajaran ini.

Berkaitan kurangnya hasil evaluasi pembelajaran ini, dan pemahaman peserta didik yang masih kurang, Guru yang berperan sebagai Peneliti mencoba mencari alternative pendekatan lain yakni pendekatan Cooperative learning dengan tehnik Example Non Example dengan materi yang akan disampaikan yakni Tema: "BERIMAN KEPADA ALLOH DAN RASULNYA" .Yang mana dalam pelajaran ini siswa dituntut untuk banyak membaca literasi terutama tentang kisah nabi dan rasul, kita jadikan metode pemahaman mereka melalui diskusi kelompok untuk lebih memahami materi, peserta didik di fungsikan sebagai subject.

Pertanyaan penelitian ini merupakan penelitian kunci, adalah Apakah Pendekatan kooperatif Learning dapat meningkatkan pemahaman terhadap materi Beriman kepada Rasu Alloh bagi siswa kelas 4 di SD Negeri 008 Balikpapan Timur? Dan Bagaimana Langkah langkah yang tepat dalam mengaplikasikan Pendekatan kooperatif learning menggunakan Tehnik example non example pada siswa kelas 4 dalam materi beriman kepada rasul Alloh?.

Sedangkan tujuan penelitian ini adalah untuk mengidentifikasi Apakah Pendekatan kooperatif Learning dapat meningkatkan pemahaman terhadap materi Beriman kepada Rasu Alloh bagi siswa kelas 4 di SD Negeri 002 Balikpapan Timur dan untuk mengetahui langkah langkah yang tepat dalam mengaplikasikan pendekatan kooperatif learning menggunakan Tehnik example non example pada siswa kelas 4 dalam materi beriman kepada rasul Alloh.

Untuk memaksimalkan hasil pembelajaran materi ini peneliti harus merencanakan proses dalam menerapkan metode ini di kegiatan pembelajaran. Agar mengetahui tingkat keefektifan model ini kami ingin membuat PTK dengan judul "Peningkatan Hasil Belajar Peserta Didik dalam mempelajari Pendidikan Agama Islam Dengan Model Cooperative Learning Dengan Tehnik Example Non Example pada peserta didik kelas 4 di SDN 002 Balikpapan Timur" 


\section{METODE PENELITIAN}

Penelitian ini merupakan penelitian tindakan kelas (classroom action research) (Sulastri et al., 2015), karena penelitian dilakukan untuk memecahkan masalah pembelajaran di kelas. Penelitian ini juga termasuk penelitian deskriptif (Sugiono, 2016), sebab menggambarkan bagaimana suatu teknik dan langkah-langkah pembelajaran diterapkan dan bagaimana hasil yang diinginkan dapat dicapai.

Penelitian ini mengacu pada perbaikan pembelajaran yang berkesinambungan. Model penelitian tindakan adalah berbentuk spiral (Rukajat, 2018). Tahapan penelitian tindakan pada suatu siklus meliputi perencanaan atau pelaksanaan observasi dan refleksi. Siklus ini berlanjut dan akan dihentikan jika sesuai dengan kebutuhan dan dirasa sudah cukup. peneliti bertugas yaitu SD Negeri 002 Balikpapan Timur pada Tahun Ajaran 2021/2022. Peneliti mengajar dalam PPL 1 rombel saja peneliti memfokuskan mengambil masalah pembelajaran yang terjadi di kelas IV SD Negeri 002 Balikpapan Timur yang berlokasi di kelurahan Lamaru Kecamatan Balikpapan Timur Kota Balikpapan. Penelitian akan dilaksanakan bulan Agustus 2021 dalam 2 siklus.

\section{Desain/Prosedur Penelitian}

Adapun untuk prosedur pelaksanaan PTK dengan menggunakan model Cooperative Learning Dengan Tehnik Example Non Example (Alexander \& Pono, 2019) peneliti berperan sebagai pelaku tindakan adapun langkah penelitianya bersifat refleksi dengan siklus: Perencanaan, tindakan, pengamatan dan Refleksi (dalam satu siklus) kemudian hasil refleksi akan berpengaruh terhadap adanya siklus kedua bila hasil refleksi menyatakan belum ada peningkatan.

Tabel 1. Langkah-langkah siklus PTK

\begin{tabular}{ll}
\hline Kegiatan & Langkah-langkah siklus \\
\hline Perencanaan & Refleksi awal \\
& Menyusun jadwal \\
& Menyusun RPP dan instrument \\
\hline Pelaksanaan & Kegiatan awal guru akan menyampaikan tujuan \\
& pemelajaran \\
& Kegiatan inti pelaksanaan KBM tema Iman kepada \\
& Rasul Alloh guru sebagai fasilitator dan siswa lebih \\
& berfungsi sebagai subjek belajar \\
& Kegiatan akhir menyimpulkan hasil diskusi \\
& kelompok tentang tema Iman kepada Rasul. \\
& Memberikan reward kepda kelompok yang berhasil \\
& menjawab dengan sempurna permasalahan yang \\
& didiskusikan. \\
& Guru akan melakukan pengamatan selama aktivitas \\
& pembelajaran \\
& $\begin{array}{l}\text { Guru akan merekam dengan baik dalam memori bisa } \\
\text { menggunakan lembar pengamatan maupun } \\
\text { membuat catatan lapangan }\end{array}$ \\
\hline Pengamatan & Guru akan menelaah kembali hasil dari observasi \\
& untuk menemukan beberapa kemungkinan yang \\
akan menjadi factor penghambat dalam KBM
\end{tabular}


Guru akan melakukan refleksi terhadap ketercapaian atau ketidak tercapaian. Refleksi ini bisa berupa kekuatan, kelemahan dari rancangan yang kita buat. Hasil Analisis dan simpulan ini akan peneliti jadikan sebagai dasar tindak lanjut pada siklus berikutnya

Dalam mendukung Penelitian kami, kami menggunakan Tehnik Pengumpulan Data sebagai berikut: Tehnik tes, "Adalah pengumpulan data dengan menggunakan serentetan soal atau tugas serta alat lainya kepada subjek yang diperlukan datanya." (Mamik, 2015, hal 73). Adapun dalam penelitian ini kami menggunakan Tehnik tes yakni Tes Hasil Belajar (Achievement Tes) dengan siswa SD Negeri 002 Balikpapan Timur kelas 4 B yang berjumlah 12 anak sebagai subjectnya, dan dilaksanakan Tehnik Non Tes.

\section{HASIL DAN PEMBAHASAN}

Hasil Belajar siswa sebelum Pembelajaran, data awal yang dapat kami gambarkan pada awal Penelitian adalah sebagai Berikut:

Tabel 2. Data Ulangan Harian Kelas 4 B

\begin{tabular}{llccl}
\hline No & Nama Siswa & KKM & Nilai & Ket \\
\hline 1 & Alby Abrisam R & 75 & 80 & Tuntas \\
2 & Aliya & 75 & 70 & Tidak tuntas \\
4 & Annisa & 75 & 70 & Tidak tuntas \\
5 & Arum septiani & 75 & 90 & Tuntas \\
6 & Ashahabil Syahidun & 75 & 60 & Tidak tuntas \\
7 & Aulia Nazila Syafa & 75 & 70 & Tidak tuntas \\
8 & Azril & 75 & 80 & Tuntas \\
9 & Bintang & 75 & 60 & Tidak tuntas \\
10 & Iqbal Maulana & 75 & 70 & Tidak tuntas \\
11 & Muhammad Taurid. A & 75 & 70 & Tidak tuntas \\
12 & Salsabila Naila muna & 75 & 90 & Tuntas \\
12 & safiya & 75 & 60 & Tidak Tuntas \\
\hline & Rata-Rata & & 72,5 & \\
\hline
\end{tabular}

Dari data ulangan harian semester 1 diatas anak kelas 4 dengan pembelajaran materi PAI dengan menggunakan Metode yang didominasi dengan teacher centered, yakni ceramah menunjukan hasil yang kurang maksimal. Dari 12 siswa yang kami jadikan object penelitian tingkat ketuntasan belajar baru 33\% dari jumlah sample yang Tuntas. Sisanya $67 \%$ belum Tuntas. Oleh karenanya kami akan mencoba meningkatkatkan Hasil belajar mereka dengan menerapkan model Pembelajaran Cooperative Learning menggunakan Tehnik Example Non Example

\section{Tindakan Siklus 1}

\section{Perencanaan siklus 1}

Perencanaan tindakan siklus 1 dalam menyusun tahap perencanaan atau untuk mempersiapkan tindakan, peneliti dibantu oleh teman sejawat .

Adapun persiapan yang kami lakukan adalah: 1 . Menusun RPP yang akan digunakan dalam pembelajaran siklus 1, 2. Menunjuk Teman sejawat sebagai observer.

\section{Pelaksanaan Tindakan siklus 1}

Siklus pertama dilaksanakan pada tanggal 12 Agustus 2021. Dalam proses pelaksanaan pembelajaran melibatkan sejumlah siswa kelas 4 SDN 002 Balikpapan Timur. Pelaksanaan 
Penerapan model cooperative learning tehnik example non example dalam meningkatan hasil belajar PAI kelas 4 di SDN 002 Balikpapan Timur

pembelajaran dilakukan berdasarkan rencana pelaksanaan pembelajaran (RPP) yang telah dipersiapkan dan berpedoman pada silabus, dan kurikulum.

Dalam pelaksanaan tindakan terdiri dari beberapa tahap yaitu: Kegiatan awal atau pembukaan pembelajaran, yang dilaksanakan selama lebih kurang 5 menit. Adapun kegiatan awal yaitu Guru dan siswa membuka proses pembelajaran dengan membaca doa, setelah itu guru mengabsen siswa kemudian membaca surah pendek pilihan,membangkitkan minat dengan menyanyi,lalu memberikan literasi, dan menjelaskan tujuan pembelajaran.dilanjutkan kegiatan inti dengan langsung membagi kelompok, dan guru memberikan apersepsi dan motivasi kepada siswa berkaitan dengan materi pelajarandengan menampilkan video pembelajaran singkat berkaitan dengan materi. kegiatan inti dilaksanakan selama lebih kurang 25menit.

Adapun aktivitas guru dalam kegiatan inti adalah: guru mempersiapkan gambar-gambar sesuai dengan tujuan pembelajaran, setelah itu, guru membagikan gambar, setelah itu guru memberi petunjuk dan memberi kesempatan pada siswa untuk memperhatikan/ menganalisis gambar, setelah itu guru memerintahkan kepada siswa untuk mencatat dari hasil diskusi kelompok mereka masing-masing, setelah itu guru memberi kesempatan kepada siswa untuk menyampaikan hasil diskusi kelompok mereka di depan kelas, dan setelah itu guru menjelaskan hasil dari diskusi kelompok siswa sesuai dengan tujuan pembelajaran, dan yang terakhir guru menyimpulkan materi pelajaran yang telah dipelajari.

Setelah kegiatan awal dan kegiatan inti dilaksanakan dilanjutkan dengan kegiatan akhir yang dilaksanakan lebih kurang 5menit, dimana dalam kegiatan akhir ini meliputi Guru memberi kesempatan kepada siswa untuk bertanya tentang hal-hal yang tidak dipahami, setelah itu guru memberikan evaluasi kepada siswa, dengan membagikan LKPD yang berupa tes tulis dengan soal Pilihan Ganda dan terakhir guru bersama siswa menutup pembelajaran dengan membaca doa dan salam. Dan hasil dari tes tulis tersebu adalah sebagai Berikut :

Tabel 3. Data Hasil Belajar Siswa Kelas 4 B Siklus 1

\begin{tabular}{llccl}
\hline No & Nama Siswa & KKM & Nilai & Ket \\
\hline 1 & Alby Abrisam R & 75 & 90 & Tuntas \\
2 & Aliya & 75 & 80 & Tuntas \\
3 & Annisa & 75 & 80 & Tuntas \\
4 & Arum septiani & 75 & 100 & Tuntas \\
5 & Ashahabil Syahidun & 75 & 70 & Tidak tuntas \\
6 & Aulia Nazila Syafa & 75 & 70 & Tidak tuntas \\
7 & Azril & 75 & 80 & Tuntas \\
8 & Bintang & 75 & 70 & Tidak tuntas \\
9 & Iqbal Maulana & 75 & 70 & Tidak tuntas \\
10 & Muhammad Taurid .A & 75 & 70 & Tidak tuntas \\
11 & Salsabila Naila muna & 75 & 100 & Tuntas \\
12 & safiya & 75 & 80 & Tuntas \\
\hline & Rata-rata & 75 & 80 & \\
\hline
\end{tabular}

Dari hasil belajar pada siklus 1 diatas terjadi peningkatan tingkat ketuntasan peseta didik meningkat menjadi 66\% siswa yang tuntas dalam siklus 1 dan 34\% masih belum Tuntas. Oleh karenanya penelitian kami anggap belum Tuntas dan akan kami lanjutkan ke siklus 2

\section{Observasi dan Refleksi siklus 1}

Pada aspek : Guru memberi petunjuk dan memberi kesempatan pada siswa untuk memperhatikan atau menganalisis gambar, dan guru memberi kesempatan kepada siswa untuk menyampaikan hasil diskusi kelompok mereka di depan kelas, dan guru menjelaskan hasil dari 
Penerapan model cooperative learning tehnik example non example dalam meningkatan hasil belajar PAI kelas 4 di SDN 002 Balikpapan Timur

diskusi kelompok siswa sesuai dengan tujuan pembelajaran, dan pada aspek guru menyimpulkan materi pelajaran yang telah dipelajari.

Pada hasil belajar siswa secara keseluruhan masih tergolong sedang dengan rata-rata persentase $66 \%$. Oleh sebab itu pada siklus selanjutnya guru lebih meningkat pada aktivitas guru pada proses pembelajaran, dan lebih memfokuskan pada aspek menjelaskan materi pelajaran, agar tujuan dari pembelajaran dapat tercapai secara maksimal.

\section{Tindakan Siklus 2}

\section{Perencanaan Sikus II}

Dalam menyusun tahap perencanaan atau persiapan tindakan pada siklus II, guru tidak mengubah dari persiapan tindakan pada siklus I, guru atau peneliti dibantu oleh teman sejawat. Adapun persiapan penelitian yang disusun adalah sebagai berikut: 1) Menyusun silabus dan Rencana Pelaksanaan Pembelajaran dengan standar kompetensi, 2) Menunjuk teman sejawat untuk menjadi observer.

\section{Pelaksanaan Tindakan Siklus kedua}

Dilaksanakan 21 Agustus 2021 dalam proses pelaksanaan pembelajaran melibatkan sebagian siswa kelas IV SDN 002 Balikpapan Timur. Pelaksanaan pembelajaran dilakukan berdasarkan rencana pelaksanaan pembelajaran (RPP) yang telah dipersiapkan dan berpedoman pada silabus, dan kurikulum.

Dalam pelaksanaan tindakan terdiri dari beberapa tahap Pelaksanaan KBM atau kegiatan belajar mengajar terdiri dari Kegiatan awal atau pembukaan pembelajaran, yang dilaksanakan selama lebih kurang 5 menit. Adapun kegiatan awal yaitu guru dan siswa membuka proses pembelajaran dengan membaca doa, setelah itu guru mengabsen siswa dan langsung membagi kelompok, dan guru memberikan apersepsi dan motivasi kepada siswa berkaitan dengan materi pelajaran dan menjelaskan pembelajaran kooperatif tipe kooperatif examples non examples. Setelah kegiatan awal selesai dilaksanakan dilanjutkan dengan kegiatan inti selama kurang lebih 25 menit

Adapun aktivitas guru dalam kegiatan inti adalah: guru mempersiapkan gambar-gambar sesuai dengan tujuan pembelajaran, setelah itu, guru menempelkan gambar di papan atau ditayangkan melalui OHP, setelah itu guru memberi petunjuk dan memberi kesempatan pada siswa untuk memperhatikan/ menganalisis gambar, setelah itu guru memerintahkan kepada siswa untuk mencatat dari hasil diskusi kelompok mereka masing-masing, setelah itu guru memberi kesempatan kepada siswa untuk menyampaikan hasil diskusi kelompok mereka di depan kelas, dan setelah itu guru menjelaskan hasil dari diskusi kelompok siswa sesuai dengan tujuan pembelajaran, dan yang terakhir guru menyimpulkan materi pelajaran yang telah dipelajari.

Setelah kegiatan awal dan kegiatan inti dilaksanakan dilanjutkan dengan kegiatan akhir, kegiatan inti dilaksanakan lebih kurang 5 menit, dimana dalam kegiatan akhir ini meliputi guru memberi kesempatan kepada siswa untuk bertanya tentang hal-hal yang tidak dipahami, setelah itu guru memberikan evaluasi kepada siswa, dan terakhir guru bersama siswa menutup pembelajaran dengan membaca doa dan salam.

Tabel 4. Data Hasil Belajar Siswa Kelas 4 B Siklus 2

\begin{tabular}{llccl}
\hline No & Nama Siswa & KKM & Nilai & Ket \\
\hline 1 & Alby Abrisam R & 75 & 100 & Tuntas \\
2 & Aliya & 75 & 90 & Tuntas \\
3 & Annisa & 75 & 80 & Tuntas \\
4 & Arum septiani & 75 & 100 & Tuntas \\
5 & Ashahabil Syahidun & 75 & 80 & Tuntas \\
\hline
\end{tabular}


Penerapan model cooperative learning tehnik example non example dalam meningkatan hasil belajar PAI kelas 4 di SDN 002 Balikpapan Timur

\begin{tabular}{llccl}
\hline 6 & Aulia Nazila Syafa & 75 & 90 & Tuntas \\
7 & Azril & 75 & 80 & Tuntas \\
8 & Bintang & 75 & 70 & Tidak tuntas \\
9 & Iqbal Maulana & 75 & 80 & Tuntas \\
10 & Muhammad Taurid .A & 75 & 70 & Tidak tuntas \\
11 & Salsabila Naila muna & 75 & 90 & Tuntas \\
12 & safiya & 75 & 80 & Tuntas \\
\hline & Rata-rata & & 84,16 & \\
\hline
\end{tabular}

Dari Tabel Hasil Belajar siklus 2 diatas, dapat diketahui bahwa dari 12 peserta didik yang kami jadikan object penelitian menunjukkan perubahan yang signifikan, dari tingkat ketuntasan mencapai $83 \%$ dari jumlah siswa yang mendapat nilai diatas KKM dan penelitian ini kami anggap cukup .

\section{Observasi dan Refleksi Aktivitas guru dalam pembelajaran kooperatif tipe examples non Example}

Berdasarkan hasil tes yang dilakukan terhadap siswa pada siklus II terlihat bahwa hasil belajar siswa masih tergolong baik dengan rata-rata 84,16. Pada tes siklus II hasil evaluasi siswa pada siklus II memperoleh persentase ketuntasan yaitu $83 \%$, angka ini berada pada interval 70 89, interval ini berada pada kategori baik.

Refleksi pada siklus kedua diperoleh berdasarkan hasil analisis data untuk tiaptiap langkah pelaksanaan tindakan yang dideskripsikan peneliti pada tahap ini. Selanjutnya didiskusikan dengan observer, yang berperan sebagai observer yaitu teman sejawat. Adapun refleksi siklus pertama adalah sebagai berikut: 1) Pada tahap perencanaan, guru telah melakukan persiapan pembelajaran dengan optimal. Kegiatan pembelajaran telah tergambar jelas pada lembaran RPP yang telah dipersiapkan dan berpedoman dengan silabus (Haslina, 2017).

Dengan demikian, pada siklus berikutnya guru tidak akan melakukan perubahan pada RPP, hanya saja lebih mengoptimalkan pelaksanaan pembelajaran sesuai dengan prosedur pembelajaran kooperatif tipe example non example untuk mencapai tujuan secara maksimal.

Aktivitas guru pada siklus II telah tergolong sempurna, karena setiap aktivitas guru yaitu langkah-langkah pembelajaran kooperatif tipe example non example. Karena penelitian ini direncanakan 2 siklus, maka pada siklus ini peneliti merangkap sebagai guru lebih mengoptimalkan pada pelaksanaan aktivitasnya, yaitu sesuai dengan langkah-langkah pembelajaran yang telah dibuat. Penelitian kami adalah penelitian tindakan Kelas yang menjadi objek penelitian adalah siswa kelas IV B di SD Negeri 002 Balikpapan Timur, dengan melakukan pembelajaran yang didalamnya menggunakan model pembelajaran cooperative learning tehnik Example Non Example.

Penelitian ini juga bertujuan untuk menambah pengetahuan peneliti mengenai model pembelajara cooperative learning tehnik Example Non Example serta bagaimana perannya dalam meningkatkan hasil belajar siswa. penelitian ini juga dapat kemi jadikan referensi dalam menyusun program pembelajaran agar hasil yang diinginkan dapat trecapai secara maksimal. Guru sebaikanya mamapu mengaplikasikan Model Pembelajaran yang bervariasi (Salehudin, 2020) sesuai dengan karakteristik siswa dan juga karaktristik materi yang akan disampaikan.

Hasil penelitian yang dilakukan dalam 2 siklus ini, menunjukkan adanya perkembangan hasil belajar siswa yang cukup signifikan. Dalam siklus 1 hasil yang dicapai memang belum tercapai sempurna , dari data awal prosetase hasil belajar siswa yang tuntas adalah $33 \%$ setelah pembelajaran siklus 1 meningkat menjadi $60 \%$ jadi mengalami peningkatan sebesar $27 \%$ Dalam siklus kedua dari data hasil belajar siswa Hasil belajar terlihat mengalami banyak peningkatan dari data awal hasil ketuntasan $30 \%$ menjadi $83 \%$ jadi mengalami peningkatan sebesar $53 \%$ persen dari keadaan awal sebelum penerapan model pembelajaran ini. Dari hasil penelitian 
Penerapan model cooperative learning tehnik example non example dalam meningkatan hasil belajar PAI kelas 4 di SDN 002 Balikpapan Timur

tersebut kami anggap cukup dilaksanakan dalam 2 siklus (Retnaningsih \& Afifah, 2019; Sembiring \& ., 2013). Walaupun belum mencapai $100 \%$ kami simpulkan bahwa penggunaan model Cooperative Learning tenik Example non Example ini dapat meningkatkan hasil Belajar siswa dalam mempelajari materi Pendidikan Agama Islam Di Sekolah Dasar Negeri 002 Balikpapan Timur, seperti pada penelitian lainnya Cooperative Learning tenik Example non Example pada hasil pembelajaran IPA (Aisah \& Asmahasanah, 2017).

\section{KESIMPULAN}

Hasil belajar PAI siswa kelas IV SDN 002 Balikpapan Timur dapat ditingkatkan melalui pembelajaran kooperatif tehnik examples non examples. Hal ini dapat dibuktikan dari hasil belajar siswa. Di mana sebelum diterapkannya pembelajaran kooperatif tipe examples non examples, rata-rata hasil belajar siswa secara klasikal hanya memperoleh nilai rata-rata 72 Setelah diterapkannya pembelajaran kooperatif tipe examples non examples, maka diketahui hasil belajar siswa siklus I pada rata-rata nilai 80 dan mengalami peningkatan Tingkat ketuntasan belajar dari kondisi awal 33\% ketuntasan menjadi $66 \%$ tingakat ketuntasan di silkus 1. Kemudian setelah refleksi dan dilakukan perbaikan terhadap kelemahan pembelajaran. Diketahui pada siklus kedua rata-rata nilai hasil belajar siswa tercapai pada nilai rata-rata 84,16 dengan kategori baik. Artinya secara klasikal siswa telah mencapai KKM yang ditetapkan, sehingga hal ini mengindikasikan keberhasilan penelitian, karena indikator keberhasilan yang ditetapkan telah melebihi $75 \%$.

Jawaban yang kedua dari pertanyaan penelitian ini dapat ditarik kesimpulan bahwa penerapan model cooperative learning sesuai dengan langkah-langkahnya yakni, 1 . Menyiapkan gambar yang akan dipakai dan disesuaikan dengan tujuan pembelajaran, 2. Guru menggunakan media OHP untuk menempel gambar yang akan ditayangkan, 3. Guru memberi instruksi yang jelas dan kesepatan bagi siswa kelas 4 untuk menganalisa gambar, 4 . Mengelompokkan siswa menjadi 3 kelompok masing masing 5 orang kemudian 5 . Melalui diskusi kelompok hasil diskusi dari analis gambar tersebut dicatat pada kertas. 6. Memberi kesempatan Tiap kelompok untuk membaca hasil diskusinya. 7. Dari hasil diskusi guru mulai menjelaskan materi sesuai tujuan yang ingin dicapai. 8. Menggiring siswa untuk menarik kesimpulan. Dengan memberikan kebebasan siswa dalam praktik berfikirnya. Bila kita lakukan dengan benar dan sistematis akan membawa dampak pada peningkatan hasil belajar siswa, serta dimodifikasi dengan menambahkan video pembelajaran akan menambah maksimal hasilnya

\section{UCAPAN TERIMA KASIH}

Terima kasih kepada Kepala Sekolah SDN 002 dan Kepala Sekolah SDN 008 Balikpapan Timur, serta guru-guru, sahabat dan teman seperjuangan.

\section{DAFTAR PUSTAKA}

Ainiyah, N. (2013). Pembentukan Karakter Melalui Pendidikan Islam. Jurnal Al-Ulum, 13(1), 2538. https:/ / doi.org/10.34005/tahdzib.v2i2.511

Aisah, S., \& Asmahasanah, S. (2017). Pengaruh Model Cooperative Learning Tipe Example NonExample Terhadap Hasil Belajar Siswa Pada Mata Pelajaran IPA. Attadib: Journal of Elementary Education, 1(2), 31-48.

Alexander, F., \& Pono, F. R. (2019). Penerapan Metode Pembelajaran Kooperatif Tipe Examples Non Examples untuk Meningkatkan Hasil Belajar Kognitif Siswa. Jurnal Ilmiah Religiosity Entity Humanity (JIREH), 1(2), 110-126.

Ariningsih, I., \& Amalia, R. (2020). Membangun karakter siswa melalui pembelajaran matematika yangg berintegrasi keislaman. Journal on Teacher Education, 1, 1-8.

Fitriani, A., Zubaidah, S., Susilo, H., \& Al Muhdhar, M. H. I. (2020). The effects of integrated problem-based learning, predict, observe, explain on problem-solving skills and selfefficacy. Eurasian Journal of Educational Research, 2020(85), 45-64. 
Penerapan model cooperative learning tehnik example non example dalam meningkatan hasil belajar PAI kelas 4 di SDN 002 Balikpapan Timur

https:/ / doi.org/10.14689/ ejer.2020.85.3

Fuadi, A. S., \& Muchson, M. (2020). Penerapan Model Pembelajaran Problem Based Learning (PBL) Pada Masa Pandemi Covid 19 Dalam Meningkatkan Aktivitas Dan Hasil Belajar Siswa Pada Mata Pelajaran Produk Kreatif Dan Kewirausahaan. SENMEA Prosiding Seminar Nasional Manajemen, Ekonomi, Akuntansi Dan Call For Paper, 23-33.

Hairiah. (2021). Model Pembelajaran Pada Masa Covid-19 di Indonesia. Journal of Instructional and Development Researches, 1(1), 1-9. https:/ / doi.org/https:/ / doi.org/10.53621/jider.v1i1.15

Haslina, Y. N. U. (2017). Kinerja Guru Dalam Implementasi Kurikulum 2013 Pada Sma Negeri 5 Lhokseumawe. Jurnal Administrasi Pendidikan : Program Pascasarjana Unsyiah, 5(4), 211-217.

Islamiah, F., Fridani, L., \& Supena, A. (2019). Konsep Pendidikan Hafidz Qur'an pada Anak Usia Dini. Jurnal Obsesi: Jurnal Pendidikan Anak Usia Dini, 3(1), 30. https:/ / doi.org/10.31004/obsesi.v3i1.132

Maryatun, I. B. (2016). Peran Pendidik Paud Dalam Membangun Karakter Anak. Jurnal Pendidikan Anak, 5(1), 747-752. https:/ / doi.org/10.21831/jpa.v5i1.12370

Muhtar, T. (2014). Analisis Kurikulum 2013 Ditinjau Dari Aspek Nilai Karakter Bangsa. Mimbar Sekolah Dasar, 1(2), 168-175. https:/ / doi.org/10.17509/ mimbar-sd.v1i2.879

Muslimin, N. (2016). Dalam Upaya Meningkatkan Mutu Pendidikan (Studi Multi Kasus di MTsN Watulimo ) Nur Muslimin. Ta'allum, 04(01), 43-61.

Retnaningsih, \& Afifah, N. (2019). Kompetensi pedagogik dan peningkatan hasil belajar ipa siswa. MODELING: Jurnal Program Studi PGMI, 6(September), 231-258.

Rukajat, A. (2018). Pendekatan Penelitian Kualitatif (Qualitative Research Approach). Deepublish.

Safaruddin, Degeng, I. N. S., Setyosari, P., \& Murtadho, N. (2020). The effect of PJBL with WBL media and cognitive style on students' understanding and science-integrated concept application. Jurnal Pendidikan IPA Indonesia, 9(3). https://doi.org/10.15294/jpii.v9i3.24628

Safaruddin, S., Ibrahim, N., Juhaeni, J., Harmilawati, H., \& Qadrianti, L. (2020). The Effect of Project-Based Learning Assisted by Electronic Media on Learning Motivation and Science Process Skills. Journal of Innovation in Educational and Cultural Research, 1(1), 22-29. https://doi.org/10.46843/jiecr.v1i1.5

Salehudin, M. (2020). Project-Based Learning Berbantuan E-Learning: Pengaruhnya Terhadap Hasil Belajar. Tadrib: Jurnal Pendidikan Agama Islam, 6(1), 28-40.

Sembiring, R. B., \& . M. (2013). Strategi Pembelajaran Dan Minat Belajar Terhadap Hasil Belajar

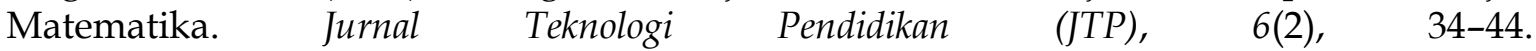
https://doi.org/10.24114/jtp.v6i2.4996

Sugiono. (2016). Metode Penelitan Kuantitatif, kualitatif dan R\&D. Bandung: Alfabeta.

Sulastri, Imran, \& Firmansyah, A. (2015). Meningkatkan Hasil Belajar Siswa Melalui Strategi Pembelajaran Berbasis Masalah Pada Mata Pelajaran IPS Di Kelas V SDN 2 Limbo mMakmur Kecamatan Bumi Raya. Jurnal Kreatif Tadulako Online, 3(1), 90-103.

Syafei, I. (2019). Pengembangan Bahan Ajar Pendidikan Agama Islam Berbasis Problem Based Learning Untuk Menangkal Radikalisme Pada Peserta Didik Sma Negeri Di Kota Bandar Lampung. Al-Tadzkiyyah: Jurnal Pendidikan Islam, 10(1), 137-158. https:/ / doi.org/10.24042/atjpi.v10i1.3631

Wati, M. (2017). Peran Guru BK dalam Membentuk Karakter Siswa Melalui Layanan BK Kelompok. PEMBELAJAR: Jurnal Ilmu Pendidikan, Keguruan, Dan Pembelajaran, 1(2), 65. https:/ / doi.org/10.26858/ pembelajar.v1i2.3482 